\title{
Icelandic history drives genetic future
}

Kari Stefansson's company is on a roll. In recent months, deCODE Genetics has announced the discovery of genes which, when mutated, increase the chances of stroke and myocardial infarction. deCODE also hopes to publish findings of an additional 11 disease genes in the coming months and aims to break into the diagnostics market next year with a test for an osteoporosis susceptibility gene. As Stefansson had hoped when he quit his tenured post at Harvard to set up the company, mining the DNA of the population of Iceland for disease genes is paying off.

deCODE's latest discovery, reported in November, is a new genetic risk factor for osteoporosis. The finding was the result of a three-year study that began with deCODE's mining of an extraordinary resource - a genealogical database of Icelanders stretching back 1,100 years. Detailed information on the ancestry of the highly homogeneous inhabitants of Iceland led to a linkage analysis that focused on the short arm of chromosome 20, a region known to contain genes involved in bone formation.

The company has now genotyped 110,000 Icelanders, almost half of the population, and these people have given written consent for use of the data in a range of disease studies. Hence, researchers have thus been able to scour the genomes of 705 people with osteoporosis, identifying variants of the bone morphogenetic protein-2 gene as resulting in a high susceptibility to osteoporosis. "We have verified this finding in a Danish population and also in an American population, [findings] which we hope will be published soon," Stefansson tells the JCI, adding, "We expect to have a diagnostic test on the market for osteoporosis next year.”

deCODE is also working to find drugs that target the genes uncovered by its population genetics research. Stefansson elaborates: "We're working in collaboration with Hoffman La Roche to develop stroke drugs on the basis of our phosphodiesterase 4D gene finding. We have a drug development program based on our isolation of a gene in schizophrenia. The most advanced program is for myocardial infarction, where we isolated a gene that makes a protein that has been used as a target for drug development in other diseases. We aim to start Phase II clinical trials before the end of this year with a compound that we have licensed from Bayer that has already been shown to be safe in humans."

Perhaps Stefansson's confidence emanates from his Viking roots - he can trace his family back to an ancestor born in 910 on the west coast of Iceland. Whatever the source, it is vital if he is to convince shareholders of the company's stability and potential success. Since its establishment in 1996, deCODE has isolated 15 disease genes and struck up collaborations with several major pharmaceutical companies. At the start of this year, it signed a deal with IBM to offer data mining technology to medical research customers. Yet deCODE has remained unprofitable.

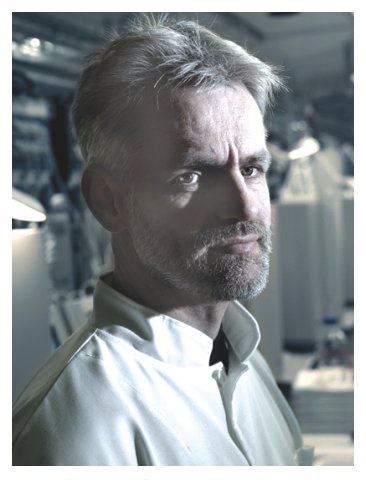

Kari Stephansson a gene inversion that represents a molecular overlap between panic disorder and bipolar disease; the second demonstrates a relationship between recombination rate and fertility, which suggests that reproductive success is associated with the generation of diversity. "We're also hoping to publish papers on the isolation of several genes for peripheral occlusive arterial disease, obesity, and asthma," says Stefansson.

Realizing that you carry a gene that renders you highly susceptible to disease gives you the chance to change your lifestyle, diet, or prophylactic drug regime. But isn't the prospect of a society focused on genetic determinism disconcerting? "Some people do not want to know," admits Stefansson. "I think it's important not to have information about yourself forced on you, although society has been doing this for a long time. For the past 30 years, if you apply for life insurance they measure your blood pressure, and for the past 15 years, they've However, Stefansson, a board-certified neurologist and neuropathologist, insists that this is about to change. "We have predicted that we will be running our company on revenue alone by the end of this year," he says. "In the third quarter we ended with more cash than we started. So we've brought the operations of this company under control through recent milestones and payments. We're here for the duration."

Like that of other biotechnology companies, deCODE's share price has suffered during the downturn in the stock market. However, its share price is currently at the highest price it has been in a year (\$9.19), and the company's finances should be bolstered further in the coming months as deCODE announces the discovery of 11 more disease genes. Two of these were reported at the November meeting of the American Society of Human Genetics. The first is tested for AIDS. What we're doing is uncovering knowledge, and knowledge in and of itself is never evil. Its application can be for good or bad. Society has to decide how it wants to manage this knowledge. I think it's important to give people the freedom to know or not."

Last year, the company isolated neuregulin 1, a candidate gene for schizophrenia on chromosome 8p. "I have an older brother who is a chronic schizophrenic, and I also have three children," says Stefansson. "I know that diseases can skip generations, so of course I'm concerned about the vulnerabilities I've been born with and those that I may have passed on to the next generation. When genetic tests are available, will I use them personally and will I encourage my kids to use them? Yes, I will."

Karen Birmingham, London 